Skin

Appendage

Disorders
Skin Appendage Disord 2018;4:108-111

DOI: $10.1159 / 000479798$
Received: May 8, 2017

Accepted: July 25, 2017

Published online: September 9, 2017

\title{
Cicatricial Alopecia in Identical Twin Lumbee Native American Women
}

\author{
Lindsay C. Strowd Jacob Subash Sean McGregor Amy McMichael \\ Department of Dermatology, Wake Forest Baptist Medical Center, Winston-Salem, NC, USA
}

\section{Established Facts}

- Central centrifugal cicatricial alopecia (CCCA) is a disease occurring mainly in African-American women.

- An autosomal dominant inheritance pattern has been observed in African families.

\section{Novel Insights}

- The presence of CCCA in twin women of Lumbee Indian descent with similar haircare practices further supports the notion that genetic factors play a role in the underlying pathophysiology of CCCA.

\section{Keywords}

Cicatricial alopecia - Scarring alopecia - Central centrifugal cicatricial alopecia - Central centrifugal scarring alopecia . Native American · Lumbee Indian

\begin{abstract}
Central centrifugal cicatricial alopecia (CCCA) has become a well-known entity occurring mainly in African-American women, but is rarely encountered in other populations. This report describes a set of identical twin Lumbee Indian women, both developing cicatricial alopecia, with one sister diagnosed with CCCA overlap with lichen planopilaris and the other with CCCA. The Lumbee Tribe is a federally recognized group of Native Americans who reside in North Carolina. Lumbee Indians have shown an increased incidence of several metabolic and neurologic diseases but cicatricial alope-
\end{abstract}

\section{KARGER}

(c) 2017 S. Karger AG, Basel

E-Mail karger@karger.com

www.karger.com/sad cia has never been an identified associated disease of the Lumbee. Thus far, no published studies have shown cicatricial alopecia as occurring in identical twins or in Native Americans. This case report discusses the issues of haircare practices and genetics in contributing to cicatricial alopecia.

(c) 2017 S. Karger AG, Basel

\section{Introduction}

Cicatricial alopecia is a category of hair loss encompassing central centrifugal scarring alopecia, lichen planopilaris (LPP), and discoid lesions of lupus erythematosus among others. Clinical features common to all forms of cicatricial alopecia include a loss of follicular ostia and follicular prominence, often centered on the vertex of the scalp. Central centrifugal cicatricial alopecia (CCCA) has 


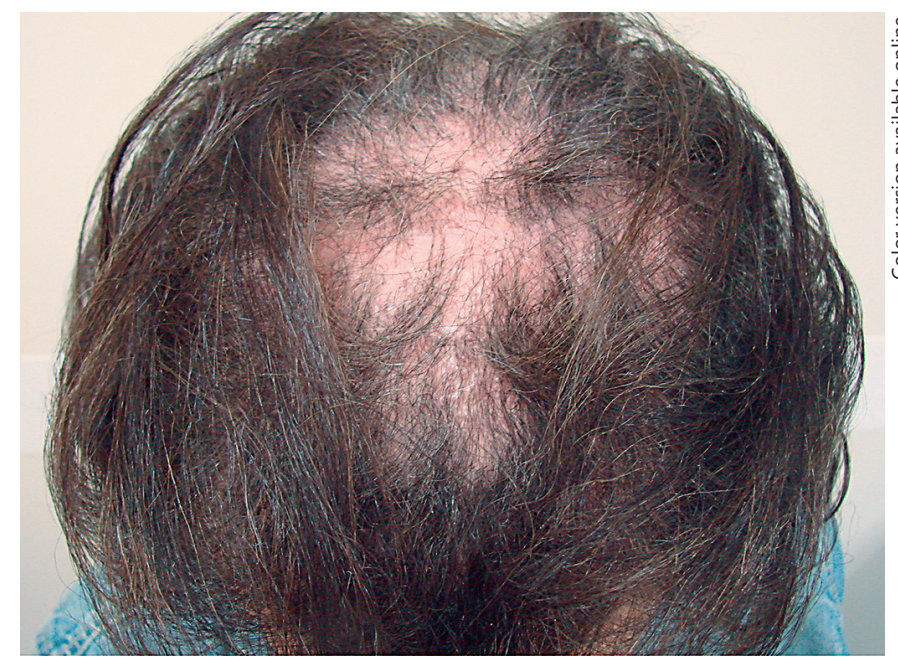

Fig. 1. Photograph of patient 1's scalp showing significant scarring alopecia of the vertex scalp.

become a well-known entity among African-American women, though the exact etiology remains unknown. There are few studies examining the epidemiology of CCCA; however, most studies show affected patients to be of African descent [1].

\section{Case Report}

Patient 1 is a 61-year-old Lumbee woman who presented to the Hair Disorders Clinic at the Department of Dermatology, Wake Forest Baptist Medical Center, Winston-Salem, NC, USA. She reported at least 10 years of progressive hair loss involving her entire scalp, most noticeable on the vertex. She denied any symptoms of itching, burning, or significant scaling. Family history was positive for hair loss in her twin sister. She denied previous scalp infections. Physical examination of the scalp showed evidence of scarring with decreased follicular ostia, erythema, and perifollicular scale. Using the Central Scalp Alopecia Photographic Scale, she was graded as level III-A (Fig. 1) [2]. Two 4-mm punch biopsies of the scalp were read as scarring alopecia with minimal inflammation, consistent with LPP. Clinical impression was most consistent with a CCCA overlap with LPP.

Patient 2 is a 61-year-old Lumbee woman who is the identical twin sister of patient 1. Patient 2 presented to the same Hair Disorder Clinic 2 years later for progressive hair loss at the recommendation of her treating dermatologist as well as her sister. She admitted to 10-15 years of hair loss involving her entire scalp. In contrast to her sister, she did complain of significant scalp scaling and itching. She had undergone punch biopsy of the scalp by an outside dermatologist 9 years prior to presentation to the Hair Disorder Clinic and this was read as scarring alopecia with sparse in-

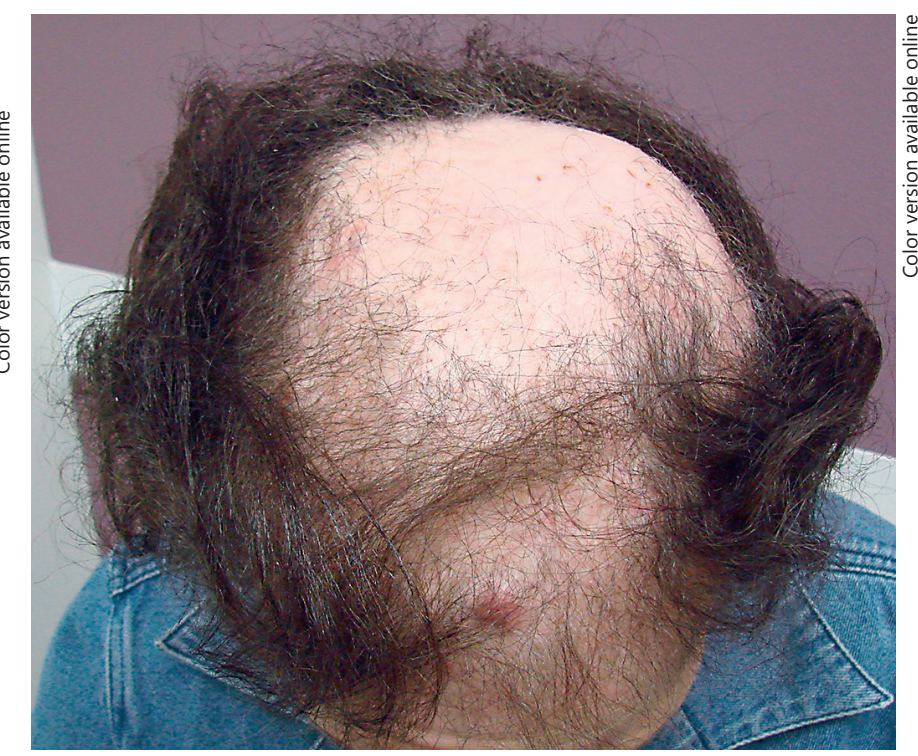

Fig. 2. Photograph of patient 2's scalp showing almost complete alopecia of the vertex scalp.

flammatory infiltrate, consistent with CCCA versus LPP. Clinical impression was consistent with CCCA. Using the Central Scalp Alopecia Photographic Scale, she was graded as a level V-B (Fig. 2) [2]

Both patients admitted to using chemical relaxers every 3-6 months since their twenties, and remembered frequent hair braiding as children. They have 3 other sisters, none of whom suffer from hair loss. There is a questionable history of hair loss in their mother. Neither patient remembered any significant prior scalp infections or other scalp disease processes. Both patients are currently being managed with topical corticosteroids for symptoms and biopsy-proven inflammation.

\section{Discussion}

The Lumbee Tribe is a federally recognized group of Native Americans who reside in North Carolina and constitute the largest tribe east of the Mississippi River. Lumbee Indians trace their heritage back to Cheraw and Sioux Indians who settled in the southeastern region of North Carolina in the 1700s [3]. Several studies have shown certain diseases to be increased in the Lumbee population including congenital myopathy and glutaric acidemia type $1[4,5]$. Searching for MeSH terms "Lumbee" and "alopecia" did not reveal any results, nor did "Native American," "alopecia," or "hair loss." Searching for the MeSH terms "alopecia" and "twins" reveals 23 results, mostly concerning alopecia areata and none regarding 
cicatricial alopecia. Dlova et al. [6] studied the pedigrees of 14 African families and found an autosomal dominant inheritance pattern. The genetic inheritance of LPP is poorly understood; there is one case report of a grandmother, mother and daughter having LPP [7]. Three pairs of identical twins were affected by frontal fibrosing alopecia, a possible variant of LPP, with a $67 \%$ concordance rate [8].

This case report highlights several interesting points. The presence of this type of alopecia in Native American women could relate to similarities between haircare practices, similarities in hair shaft structure, or shared ancestry with women of African descent. The majority of African-American hairs are spiral-shaped with curved scalp follicles. The hairs have an elliptical cross-section, which differs from Native American hairs which typically have a rounder cross-sectional shape [9]. However, the study that examined the Native American hairs looked at members of the Hopi, Navajo and Zuni tribes. It may be that the Lumbee tribe shares more genetic similarities with those of African descent than the aforementioned tribes and that may explain the presence of cicatricial alopecia. The two women in this case report have Fitzpatrick type IV skin but have hair that is fairly coarse and closely resembles African-American hair. Similar haircare practices in these women may also contribute to the development of cicatricial alopecia, as hair braids and other traction-induced styling techniques have been implicated in CCCA $[1,10]$.

The fact that not all African-American women experience cicatricial alopecia and a single causative haircare practice has not been found suggests that there may also be a component of genetic susceptibility. Some studies indicate familial inheritance of cicatricial alopecia, though other types of alopecia have more clear genetic and familial associations $[6,11-13]$. In reports of South African families, clinical and histologic evidence of CCCA has been found in women and their immediate family members $[6,13]$. The severity of disease was worse in those family members with a history of chemical or mechanical hair trauma $[6,12]$. Thus, a genetic defect could be viewed as the primary event in the underlying pathophysiology of the disease with environmental exposures or practices activating the disease process $[6,10,13]$. The case of these identical twin women both developing cicatricial alopecia with no evidence of hair loss in their sisters strongly suggests an underlying genetic component. Despite nearly identical haircare practices, they differ in the severity of their cicatricial alopecia, and also the specific histologic appearance of the infiltrate on biopsy. A confounding variable is that the biopsies were obtained at two different institutions and read by different dermatopathologists.

This case report will inform dermatologists working with Native Americans on the susceptibility of this population to cicatricial alopecia, and will contribute to the current body of literature suggesting a familial component to this subset of alopecia. Further studies are needed to elucidate the pathogenesis of CCCA and identify other at-risk populations.

\section{Statement of Ethics}

Subjects have given their informed consent and the study protocol has been approved by the institute's committee on human research.

\section{Disclosure Statement}

The authors have no conflicts of interest to disclose.

\section{Author Contribution}

Drs. A. McMichael, L.C. Strowd, S. McGregor, and J. Subash had full access to all of the data in the study and take responsibility for the integrity of the data and the accuracy of the data analysis. All authors concur with the submission of the manuscript. Study concept and design: A. McMichael, L.C. Strowd. Acquisition of data: A. McMichael, L.C. Strowd, S. McGregor. Drafting of the manuscript: A. McMichael, L.C. Strowd, J. Subash, and S. McGregor. Critical revision of the manuscript for important intellectual content: A. McMichael, L.C. Strowd, S. McGregor, and J. Subash. Financial disclosure: none reported. Subjects have given their informed consent and the study protocol has been approved by the institute's committee on human research.

\section{References}

1 Gathers RC, Lim HW: Central centrifugal cicatricial alopecia: past, present, and future. J Am Acad Dermatol 2009;60:660-668.

2 Olsen EA, Callender V, Sperling L, McMichael A, Anstrom KJ, Bergfeld W, Durden F, Roberts J, Shapiro J, Whiting DA: Central scalp alopecia photographic scale in African American women. Dermatol Ther 2008;21: 264-267.

3 Lumbee Tribe of North Carolina. http://www. lumbeetribe.com/History_Culture/History_ Culture\%20Index.html (accessed June 20, 2011).

4 Basinger AA, Booker JK, Frazier DM, Koeberl DD, Sullivan JA, Muenzer J: Glutaric acidemia type 1 in patients of Lumbee heritage from North Carolina. Mol Genet Metab 2006; 88:90-92. 
5 Stamm DS, Powell CM, Stajich JM, Zismann VL, Stephan DA, Chesnut B, Aylsworth AS, Kahler SG, Deak KL, Gilbert JR, Speer MC: Novel congenital myopathy locus identified in Native American Indians at 12q13.13-14.1. Neurology 2008;71:1764-1769.

6 Dlova NC, Jordaan FH, Sarig O, Sprecher E: Autosomal dominant inheritance of central centrifugal cicatricial alopecia in black South Africans. J Am Acad Dermatol 2014;70:679682.e1.

7 Misiak-Galazka M, Olszewska M, Rudnicka L: Lichen planopilaris in three generations: grandmother, mother, and daughter - a genetic link? Int J Dermatol 2016;55:913-915.
8 Tziotzios C, Stefanato CM, Fenton DA, Simpson MA, McGrath JA: Frontal fibrosing alopecia: reflections and hypotheses on aetiology and pathogenesis. Exp Dermatol 2016;25: 847-852.

9 Taylor SC: Skin of color: biology, structure, function, and implications for dermatologic disease. J Am Acad Dermatol 2002;46(2 suppl understanding):S41-S62.

10 Ogunleye TA, McMichael A, Olsen EA: Central centrifugal cicatricial alopecia: what has been achieved, current clues for future research. Dermatol Clin 2014;32:173-181.
11 Schweiger ES, Boychenko O, Bernstein RM: Update on the pathogenesis, genetics and medical treatment of patterned hair loss. J Drugs Dermatol 2010;9:1412-1419.

12 Redler S, Brockschmidt FF, Forstbauer L, Giehl KA, Herold C, Eigelshoven S, Hanneken S, De Weert J, Lutz G, Wolff H, Kruse R, Blaumeiser B, Böhm M, Becker T, Nöthen MM, Betz RC: The TRAF1/C5 locus confers risk for familial and severe alopecia areata. $\mathrm{Br}$ J Dermatol 2010;162:866-869.

13 Dlova NC, Forder M: Central centrifugal cicatricial alopecia: possible familial aetiology in two African families from South Africa. Int J Dermatol 2012;51(suppl 1):17-20, 20-23. 